\title{
The Use of Microemusion Systems in Oil Industry
}

\author{
Vanessa Cristina Santanna, Tereza Neuma de Castro Dantas \\ and Afonso Avelino Dantas Neto \\ Federal University of Rio Grande do Norte \\ Brazil
}

\section{Introduction}

Microemulsions are thermodynamically stable, isotropic, and macroscopically homogeneous dispersions of two immiscible fluids, generally oil and water, stabilized with surfactant molecules, either alone or mixed with a cosurfactant, as shown in Figure 1 (Robb, 1981). Cosurfactant is a nonionic molecule (e.g. a short-chain of alcohols or amine) that has the function of stabilizing a microemulsified system by decreasing the repulsion forces between the hydrophilic parts of the surfactant.

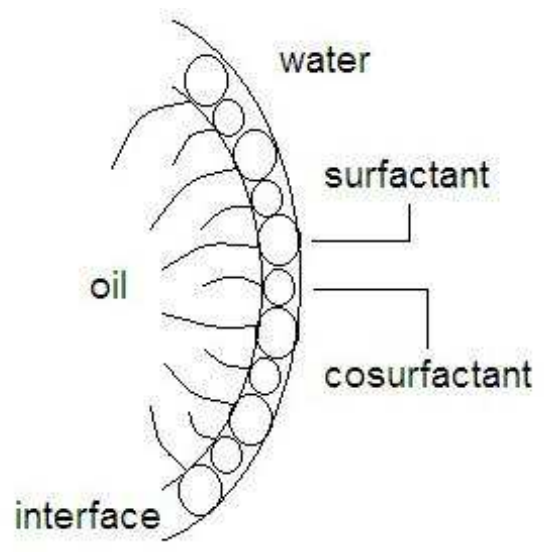

Fig. 1. Microemulsion droplet (Reversed micelle)

The potential of microemulsions in technological applications, however, has not yet fully been explored. Presently, there are many established industrial activities that rely on the use of emulsions as a mean to achieve effectiveness. It is important to consider the core differences between emulsions and microemulsions to improve the design of their applications, as shown in Table 1.

Microemulsion equilibriums, according to Winsor's classification (Friberg \& Bothorel, 1987), vary according to the nature of the phases involved (Figure 2). This classification establishes 
four types of systems: WINSOR I (WI), where the microemulsion phase is in equilibrium with an organic phase in excess; WINSOR II (WII), where the microemulsion phase is in equilibrium with an aqueous phase in excess; WINSOR III (WIII), where the microemulsion phase is in equilibrium with both aqueous and organic phases (three-phase system); and WINSOR IV (WIV), which is a one-phase system, in a macroscopic scale.

\begin{tabular}{|l|l|}
\hline \multicolumn{1}{|c|}{ Emulsions } & \multicolumn{1}{c|}{ Microemulsions } \\
\hline Unstable, with eventual phase separation & Thermodynamically stable \\
\hline Relatively large-sized droplets $(1-10 \mu \mathrm{m})$ & $\begin{array}{l}\text { Small aggregates (around a few tens of } \\
\text { nanometers) }\end{array}$ \\
\hline Relatively static systems & Highly dynamic systems \\
\hline Moderately large interfacial area & Very high interfacial area \\
\hline $\begin{array}{l}\text { Small amount of surfactant required for } \\
\text { stabilization }\end{array}$ & $\begin{array}{l}\text { Large amount of surfactant required for } \\
\text { stabilization }\end{array}$ \\
\hline Low curvature of the water-oil interface & Interfacial film may be highly curved \\
\hline
\end{tabular}

Table 1. Main differences between emulsions and microemulsions (Dantas Neto et al., 2009)

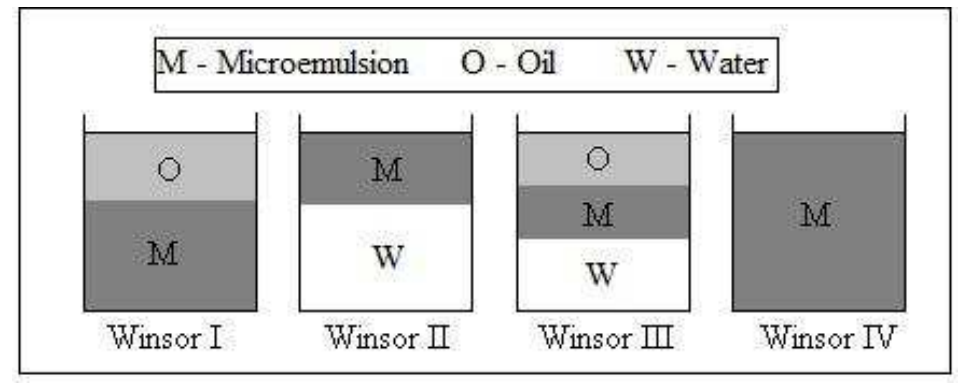

Fig. 2. Schematic showing Winsor's classification

The microemulsions, composed of four constituents (water, oil, surfactant, and/cosurfactant), can be represented by pseudoternary diagrams, built and displayed in a user-friendly manner. In order to simplify the microemulsion's representation, two constituents are kept in a fixed proportion, the "pseudoconstituent". The constant molar ratio (cosurfactant/surfactant) is usually applied during this phase as demonstrated in Figure 3. To determine the Winsor's regions in a pseudoternary diagram, the oil phase was mixed with the surfactant/cosurfactant phase, and the mixture was titrated with water to observe the changes in the Winsor's regions. The volume of water used was determined for each region change. The pseudoternary phase diagram was constructed by plotting the amounts of water, oil, and surfactant/cosurfactant phases.

Microemulsified media are of great interest due to its wide potentialities for industrial applications, such as in the oil industry. Therefore, this paper aims to show the applications of microemulsions in various areas of the oil industry, such as in wells' hydraulic fracturing (stimulation operation), as corrosion inhibitors in pipelines, in the breakdown of water/oil emulsions, in enhanced oil recovery, and as an alternative fuel. 


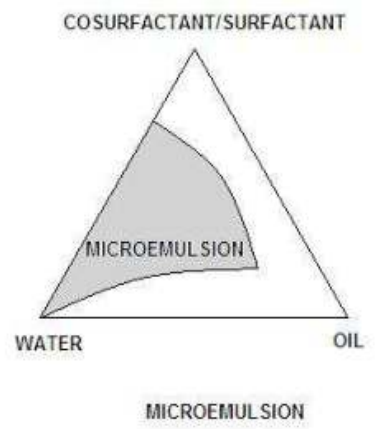

Fig. 3. Pseudoternary diagram with constant cosurfactant/surfactant ratio

\section{Microemulsions in oil industry}

\subsection{Hydraulic fracturing}

Hydraulic fracturing is a technique that aims to increase well productivity. The fracturing fluid is applied against the reservoir rock under high differential pressure to create fractures. A proppant (sand, bauxite, or ceramic) is pumped into the well with the fracturing fluid to keep the fracture open; creating a high conductivity way that eases the flow of fluids between the formation point and the well. In recent years, the insoluble residues of fracturing fluids left in the fracture have been the object of more specific studies. These fluids can cause damage (permeability reduction) in the proppant pack or on the surfaces of the fracture itself. Hence, fracturing fluid, microemulsion-based category, has been reported to reduce the formation of damage. Surfactant-based fracturing gels (microemulsions) are considered clean gels due to the absence of insoluble residues in its composition.

Samuel et al. (1999) developed a surfactant-based polymer-free fluid (ClearFRAC). The surfactant used was a quaternary ammonium salt, derived from a long-chain fatty acid. Aspects such as structure, rheology, fluid loss, and conductivity of this surfactant fluid were studied. The results showed that, in brine, the fluid's viscosity and viscoelasticity occurs due to the formation of highly entangled worm-like micelles. The micelles have a gross structure similar to a polymer chain. Since the viscosity of the fluid depends on the nature of micelles, the fluid can be broken by changing its micellar structure. The breaking occurs when the fluid is exposed to hydrocarbons or diluted with formation water. Therefore, conventional breakers are not required, and the produced oil or gas can act as breakers for this fluid system.

Castro Dantas et al. (2003a) developed a surfactant-based fracturing gel (SBG). The formulation of a viscous microemulsion system (gel) was obtained from the pseudoternary phase diagram as illustrated in Figure 4. The gel's composition was 18 wt. \% soap, 9 wt. \% isoamyl alcohol, $14 \mathrm{wt}$ \% pine oil, and $59 \mathrm{wt}$. \% water. Comparisons between the SBG and conventional gel (Hydroxypropylguar - HPG) were performed. The API (American Petroleum Institute) fluid loss test was performed and the fluid loss values for the SBG were 21 times larger than the ones for the conventional gel. This was because surfactant-based gels are free of solids and do not form a filter cake and the interactions between the microemulsion microdroplets are very weak, allowing the gel to flow through the filtration medium with little resistance, if compared to HPG. Two fluid-loss additives were used: 
silica-flour $\left(6 \mathrm{~kg} / \mathrm{m}^{3}\right)$ and a urea solution (1-8\%). The authors observed a $14 \%$ reduction of filtrate for SBG and a 20\% reduction for HPG, when silica-flour was used in the experiment. The urea is a bi-functional and cationic salt that links an anionic micelle to another, increasing the viscosity of the gel and reducing the filtrate. With the addition of a urea solution, the leak-off coefficient had a reduction of up to $50 \%$ for the SBG. The capacity of gels to sustain the ceramic 16/20 mesh in function of time also was observed, and the SBG presented a great sustaining capacity for the proppant (Table 2). The authors concluded that the SBG presented compatible characteristics when compared with the HPG gel.

\begin{tabular}{|c|c|}
\hline Gel type & $\left.\mathbf{v}_{\mathbf{s}} \mathbf{( c m} / \mathbf{s}\right)$ \\
\hline HPG & 1.63 \\
\hline SBG & $1.17 \times 10^{-3}$ \\
\hline
\end{tabular}

Table 2. Results of setting rate assays of surfactant-based fracturing gel (SBG) and Hydroxypropylguar gel (HPG) (Castro Dantas et al., 2003a)

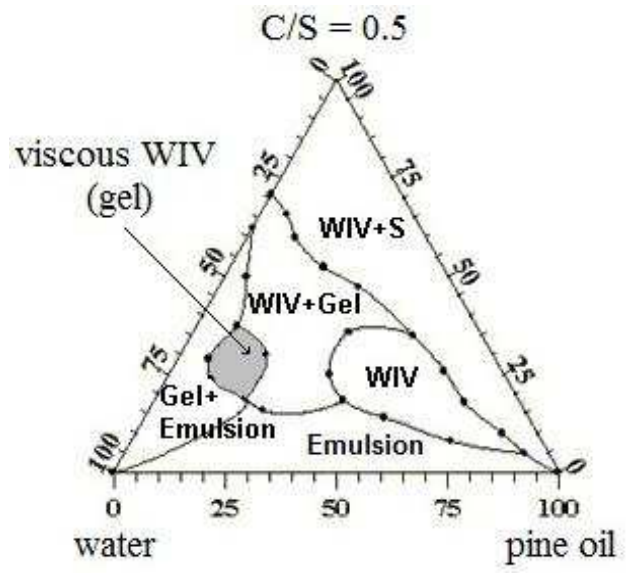

Fig. 4. Pseudoternary system comprising distilled water, commercial surfactant (S), pine oil, isoamyl alcohol $(\mathrm{C})$, with $\mathrm{C} / \mathrm{S}$ ratio $=0.5$, constructed at $26^{\circ} \mathrm{C}$ (Dantas et al., 2003a)

Depending on the surfactant concentration and temperature, micelles of different geometry are formed, such as spheres or rods. The determination of the inner structure of surfactant solutions through optical measurements is possible only when the surfactant concentration is very low and the solution is at rest. Rheological measurements offer an indirect way to determine the inner structure of surfactant solutions over a wide concentration range, and often can provide evidence of structural changes. On this subject, Castro Dantas et al. (2003b) performed rheological studies to evaluate the inner structure of anionic surfactantbased gels. Steady and oscillatory shear experiments were carried out. To prepare the surfactant-based gels, the gel region (viscous microemulsion) in the pseudoternary phase diagram was determined (Figure 5). In steady shear experiments, the temperature ranged from 26 to $86^{\circ} \mathrm{C}$. In oscillatory shear experiments the shear stress was maintained constant $(1$ $\mathrm{Pa}$ ) and all of the experiments were done at $66^{\circ} \mathrm{C}$. In order to check the pseudoplastic (shear thinning) behavior of the gel, rheological tests were performed by varying the shear rate from 0.01 to $120 \mathrm{~s}^{-1}$. Four compositions of gels were chosen as shown in Table 3. 


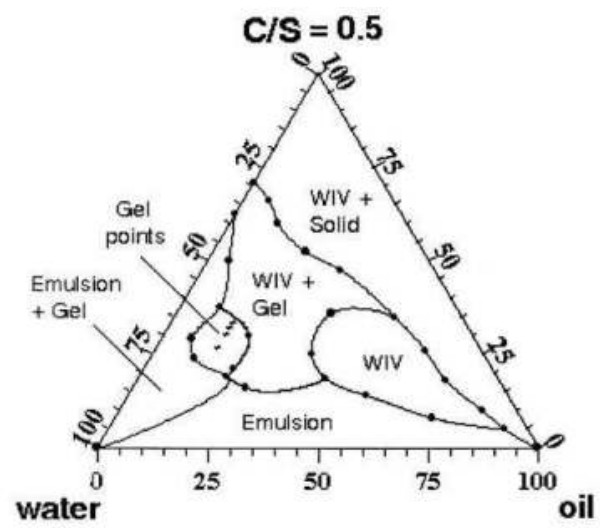

Fig. 5. Pseudoternary phase diagram showing the gel region with the four compositions chosen $\left(26^{\circ} \mathrm{C}\right)$ (Castro Dantas et al., 2003b)

\begin{tabular}{|c|c|c|c|c|}
\hline $\begin{array}{c}\text { Gel } \\
\text { Cosurfactant/Surfactant } \\
(\mathbf{w t} \text { \%) }\end{array}$ & $\begin{array}{c}\text { Surfactant } \\
\text { Soap } \\
(\mathbf{w t} \text { \%) }\end{array}$ & $\begin{array}{c}\text { Cosurfactant } \\
\text { isoamyl alcohol } \\
\text { (wt \%) }\end{array}$ & $\begin{array}{c}\text { Oil- } \\
\text { pine oil } \\
(\mathbf{w t} \text { \%) }\end{array}$ & $\begin{array}{c}\text { Water } \\
\mathbf{( w t ~ \% )}\end{array}$ \\
\hline 27 & 18 & 9 & 14 & 59 \\
\hline 30 & 20 & 10 & 14 & 56 \\
\hline 32 & 21.3 & 10.7 & 14 & 54 \\
\hline 34 & 22.7 & 11.3 & 14 & 52 \\
\hline
\end{tabular}

Table 3. Compositions of gels for rheological studies

Based on oscillatory shear experiments, the authors concluded that the micellar structure exhibits a viscoelastic response typical of gel-like materials, characterized by loss and storage modulus slightly dependent on frequency. In steady shear experiments, they verified that the viscosity of the gels depends on $\mathrm{C} / \mathrm{S}$ concentration and temperature as illustrated in Figure 6. The increase in viscosity with C/S concentration is attributable to the dispersed fraction in the solutions (micelles), to the nature of the micelle aggregates, and to the structure-forming interactions between the aggregates. From the gel-activation energies, the authors verified, that the activation energy is positive when there is a small variation of the volume of the micelles and negative when the volume variation of the micelles prevails in the system.

Castro Dantas et al. (2006) developed a laboratory break methodology for surfactant-based fracturing gel (SBG). According to the authors, fracturing gel should provide sufficient viscosity to suspend and transport the proppant into the fracture, and should break into a low-viscosity fluid after the fracturing is completed. This break facilitates the fracture cleaning by allowing a rapid counter flow of fluids to the surface. Surfactant-based fracturing gels can be broken when exposed to hydrocarbons or formation water. Therefore, conventional breakers, commonly used in polymer-based gels, are not required and the oil or produced gas can act as breakers for surfactant-based gels. The gel break test consisted basically of the injection of fluids into sandstone core samples as seen in Figure 7. To simulate reservoir conditions, brine and oil were injected into the core sample (Figure 8). 
The surfactant-based gel (18 wt. \% soap, 9 wt. \% isoamyl alcohol, 14 wt. \% pine oil, and 59 wt. \% water) was then injected at a constant flow rate, in the opposite direction to oil production and samples were collected. Initially, the samples had some oil content, then, limpid samples were observed. These samples were collected at periods of time determined previously. The gel break was verified by assessing its viscosity in a Brookfield rheometer at $26{ }^{\circ} \mathrm{C}$. The authors observed that the gel broke within the first hours of the tests due to the initial presence of oil and brine in the core. When oil and/or water were introduced into surfactant-based gels, the micelles moved apart and the viscosity decreased. They observed that the studied gel presented optimum break results, due to a viscosity decrease to $10 \mathrm{mPas}$ in the first 6 h of the test as seen in Figure 9.

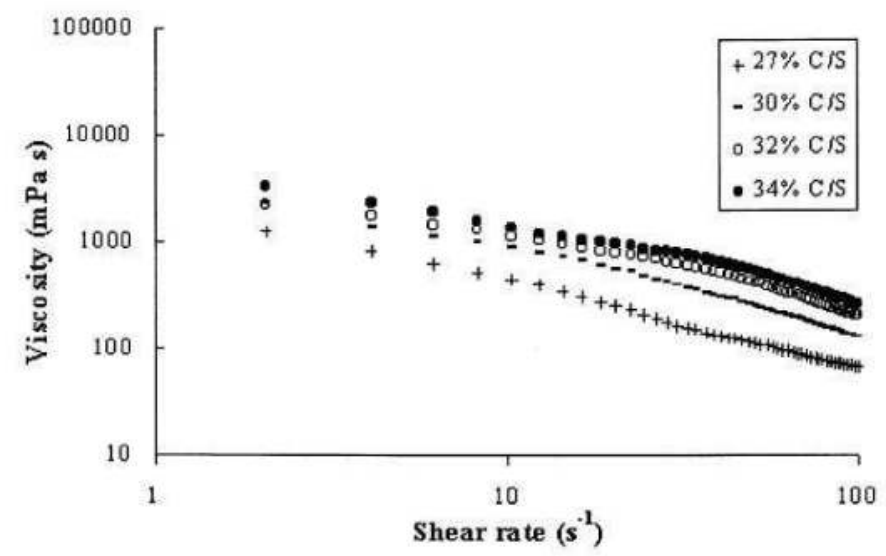

Fig. 6. Results of assays showing rheological behavior of surfactant-based gel (Castro Dantas et al., 2003b)

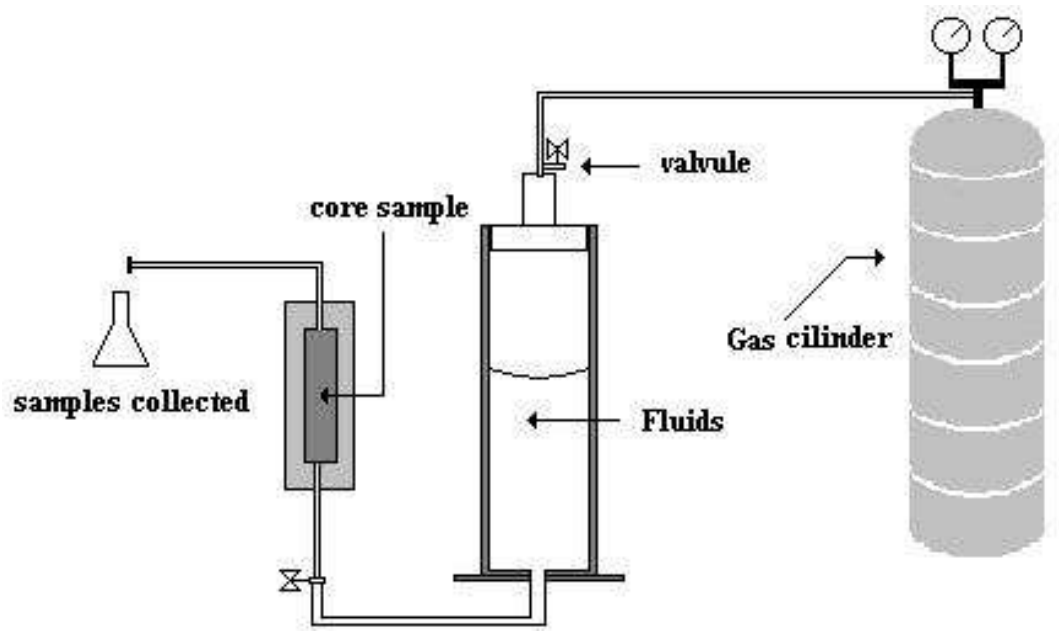

Fig. 7. System developed for the break tests with surfactant-based gels (Castro Dantas et al., 2006) 


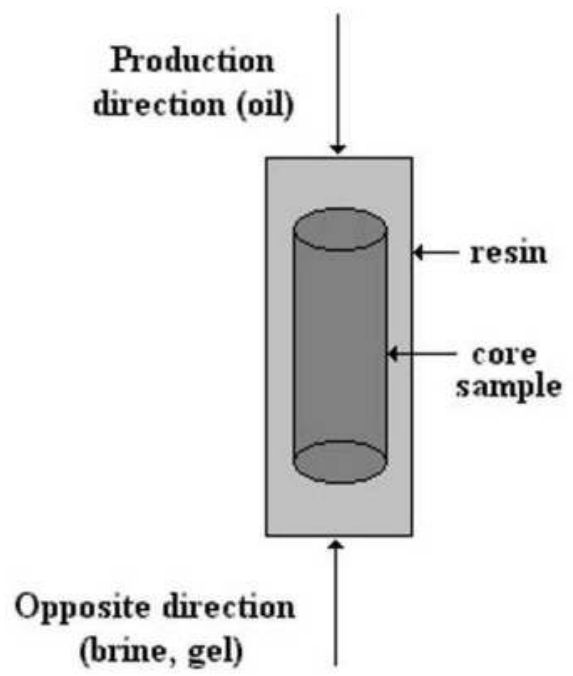

Fig. 8. Schematic diagram showing the flow directions used in the gel break tests (Castro Dantas et al., 2006)

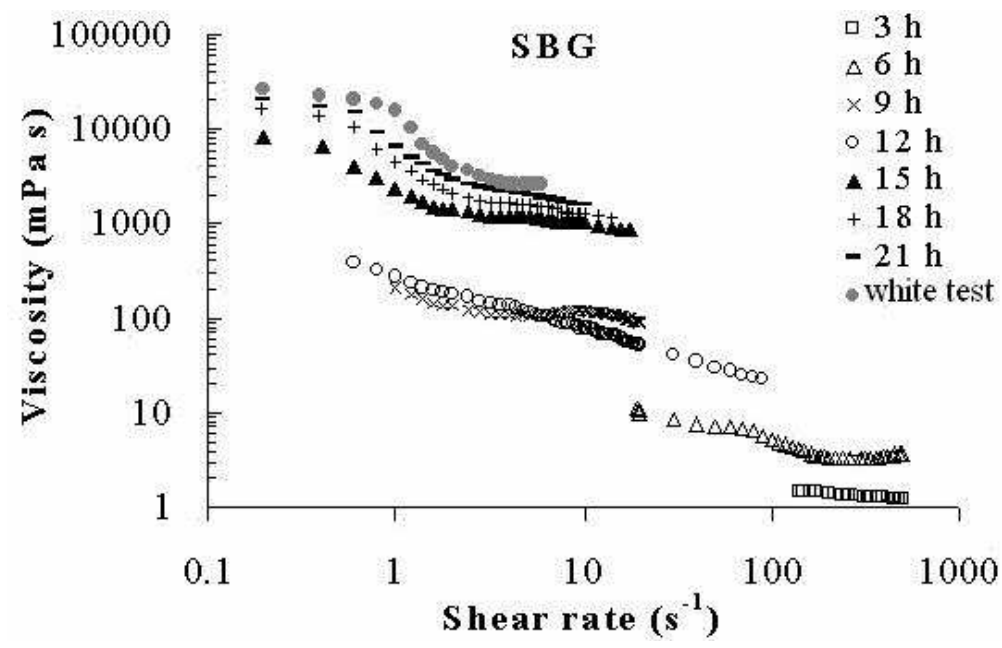

Fig. 9. Surfactant-based gel break results (Castro Dantas et al., 2006)

Recently, Liu et al (2010) observed the benefits of applying the microemulsion together with a polymer in hydraulic fracturing. The authors constructed a fracturing fluid which they named SPME-Gel with a combination of a single phase microemulsion (SPME) and a gelable polymer system. The formulation of a single phase microemulsion system was obtained from the pseudoternary phase diagram. The SPME composition was 22-27\% $\mathrm{w} / \mathrm{w}$ Tween-80 and Span-80 (2:1 ratio), $24-26 \% \mathrm{w} / \mathrm{w}$ kerosene, $21-23 \% \mathrm{w} / \mathrm{w}$ isopropanol and $27-29 \% \mathrm{w} / \mathrm{w}$ tap water. The SPME-Gel formulations were prepared by adding SPME into a gelable polymer system (Hydroxypropyl guar gum- HPGG) at various 
concentrations (1000-5000 mg/L). A series of comparative experiments were performed with the SPME-Gel and conventional gel (without SPME). API fluid loss was performed and the fluid-loss values of SPME-Gels were half of the conventional gel ones. This difference can be attributed to the assembly of micelles in a group forming microscopic spheres, rods, and plates that can create a deformable barrier, reducing leak off protection on the surface of the fractured rock. The effectiveness of breakage was studied. The results showed that in the broken SPME-Gel systems, the HPGG residues were stably suspended, while for the broken conventional gel, the HPGG residues were deposited. This indicates that the broken SPME-Gel system has remarkable suspension capability for HPGG residues. This property shows that in the SPME-Gel system less HPGG residues remained in formation after gel breakage. Core permeability regaining tests indicated that 83 to $91 \%$ of the original matrix permeability was regained after exposure to SPME-Gel, while only 51 to $62 \%$ was regained by the conventional gel. Proppant conductivity tests were performed and the results indicated that 90 to $96 \%$ of the proppant's conductivity was regained for SPME-Gels, against 68 to $77 \%$ for the conventional gels. From the measurements obtained, it was observed that properties of SPME-Gels were more predominant than those of conventional gels. Thus, SPME-Gel is a promising formula that offers advantages for reducing formation damage, lowering the initial cleanup pressure, and maintaining the original core regain for fracturing treatment.

\subsection{Break down emulsions}

Fluids injected during the drilling and completion process, with the aim of cleaning up the well, can cause formation damages due to rock pore clogging. Acid solutions, added later to restore the permeability of the rock, can promote the formation of highly viscous emulsions and dregs. This will cause a significant reduction in production and even compromise viable economic exploitation. The formation of emulsions and dregs is a serious problem during the well stimulation process and can result in large losses of oil (Castro Dantas et al., 2001). Many studies have proposed alternatives to break down emulsions, such as application of microemulsions.

Castro Dantas et al. (2001a) studied the performance of microemulsion systems as an alternative in the breakdown of petroleum emulsions. The crude oils used were characterized by the different Balance Sheet of Sediment and Water (BSW) values of $48 \%$, $36 \%$, and $32 \%$. The microemulsion systems studied were composed of $\mathrm{HCl} 5.2 \%$ solution; toluene; and isopropyl alcohol (C)/surfactants (S), with a ratio C/S of 9.0. The commercial surfactants used were Dissolvan, NE-8, Dentrol, OC595, Fenoil, Polimus-43, NE-9, Polimus22, Dehydet, and Ultrapan. The microemulsion efficiency to break down oil emulsions was evaluated by using the direct contact method between the microemulsions and crude $(\mathrm{W} / \mathrm{O})$ emulsions in graduated centrifuge tubes for $30 \mathrm{~min}$, under stirring at $70^{\circ} \mathrm{C}$. The results showed the achievement of a good percentage of emulsions breakdown for all systems. The results indicated that the breakdown efficiency is directly dependent on the microemulsion composition and the physicochemical properties of the oil. Dissolvan can efficiently be used in microemulsion systems, which their compositions are in the oil-rich phase and with $\mathrm{C} / \mathrm{S}$ percentages from $60 \%$ to $82 \%$, to break down $100 \%$ of the oil emulsion. The NE- 8 showed to be efficient in aqueous phase rich microemulsion regions for all $\mathrm{C} / \mathrm{S}$ percentages, being able to completely break down the oil emulsion. With the Polimus- 43 in oil-rich and/or aqueous- 
rich phase microemulsion regions, $100 \%$ of emulsion breakdown was obtained. The authors concluded that some commercial surfactants used for the formation of microemulsion systems were able to completely break down oil emulsions formed during production operations of Brazilian petroleum fluids.

\subsection{Corrosion inhibitor}

In the petroleum industry, saline media is the main agent that leads to corrosion. It acts in the inner walls of oil pipelines, leading to a particular type of corrosion, which is commonly referred to as localized pitting corrosion. Surfactant molecules have been employed as corrosion inhibitors in order to minimize and control such phenomenon. Surfactant molecules form films on metallic surfaces that protect them from corrosion by impairing the action of electrolytes. The adsorption of surfactants on metal surfaces depends on the structure and concentration of surfactant molecules in the contacting medium determining the final adsorption layout with the formation of monolayers (Figure 10) or multilayers of surfactant molecules (Reyes et al., 2005).

\section{Surfactant molecules}

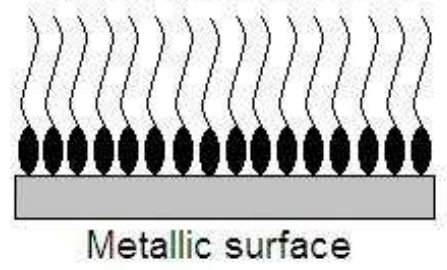

Fig. 10. Monolayers formed by adsorbed surfactant molecules onto a metallic surface

The microemulsions also have the characteristic of adsorbing onto interfaces. When microemulsions are used, an oil film is adsorbed onto the surface with the surfactants tails oriented towards it, in view of the usually positive character of the surface.

The anticorrosion capacity can be tested by electrochemical cells. Three electrodes normally are used in such assays, a reference electrode, a counter electrode, and a work electrode. These electrodes are immersed in the corrosive medium, which can be a saline or acidic solution, with or without an inhibitor. The reference electrode is involved directly in the corrosion potential measurements, from which anodic and cathodic polarizations are affected. The counter electrode is used as an auxiliary to complete the cell and balance charges. The efficiency of the system in inhibiting corrosion (E \%) is estimated by means of Equation 1:

$$
\mathrm{E} \%=\left[100 \times\left(\mathrm{I}_{\text {corr }}-\mathrm{I}_{\text {corr }}^{\prime}\right)\right] / \mathrm{I}_{\text {corr }}
$$

where, $\mathrm{I}_{\text {corr }}$ and $\mathrm{I}_{\text {corr }}$ denote the corrosion current densities in the absence and presence of inhibitor, respectively.

Using potentiometry measurements, Moura et al. (2009) studied the anticorrosion ability of three novel surfactant molecules in solution and microemulsion media. The surfactants were synthesized from ricinoleic acid, a castor oil derivative (sodium 12-N, N-diethylamino-9- 
octadecenoate- AR1S, sodium 12-N, N-diethylamino-9, 10-dihydroxy-octadecanoate- AE2S and sodium 12-N, N-diethylamino-9-octadecanoate- AE1S) as shown in Figure 11. The ability to inhibit corrosion was investigated by preparing specific micellar solutions and microemulsion systems. The microemulsions components used were: the synthesized surfactants (AR1S, AE2S and AE1S); a saline aqueous solution $(\mathrm{NaCl} 0.1 \mathrm{M})$; $n$-hexane and butan-1-ol, with a constant $\mathrm{C} / \mathrm{S}$ concentration ratio equal to 2 . Adsorption phenomenon was studied electrochemically and the Frumkin isotherm model indicated that the surfactant solutions tested can inhibit corrosion with levels as high as $95 \%$. The authors verified that the chemical groups attached to the hydrocarbon chains of the AE2S and AE1S molecules enable adsorption phenomena with different levels of intensity at the surface. When in solution, surfactants behave as better inhibitors, if compared to microemulsion systems. This comparision provides clear evidence that the adsorption promoted by micellar solutions is stronger than microemulsion systems. Microemulsion systems also interact with the metallic surface, although via a less intense physical mechanism. On the other hand, the microemulsion systems, although featuring relatively lower performance, are advantageous considering that they are able to dissolve more active matter.

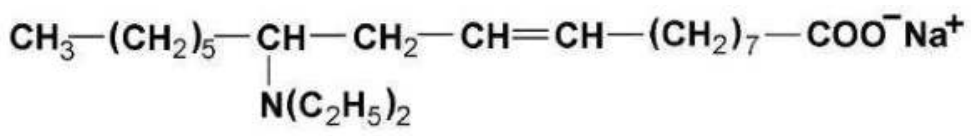<smiles>CCCCCCCCCC(O)C(O)CC(=O)O[NH3+]</smiles><smiles>CCCCCC(CCC(=O)O[NH3+])N(CC)CC</smiles>

Fig. 11. Molecular structures of the synthesized surfactants AR1S, AE2S and AE1S, respectively (Moura et al., 2009)

\subsection{Enhanced oil recovery}

The application of enhanced oil recovery methods (tertiary oil displacement process) has been investigated with the purpose of responding to the demands of energy supply. (Santanna et al., 2009).

Petroleum recovery methods basically consist of the injection of fluids onto the rock with the objective of displacing oil out of the rock pores, where it is impregnated. The injected fluid may be known as displacing fluid and it pushes the oil out of the rock. At the same time, the injected fluid occupies the empty space left by the displaced fluid that was expelled. Enhanced oil recovery methods are classified in three distinct categories: thermal methods, miscible methods, and chemical methods. Microemulsion flooding is included into chemical methods classification. 
In enhanced oil recovery, the microemulsion flooding has been suggested as an alternative method. It displays the unique properties of microemulsion systems, such as high viscosity and the ability to induce low interfacial tension, increasing oil extraction efficiency (Santanna et al, 2009). According to Austad and Strand (1996), very low interfacial tensions may be reached with microemulsion systems. According to Gurgel et al. (2008) microemulsions are potential candidates in enhanced oil recovery, especially because of its ultra-low interfacial tension values, attained between the contacting oil and water microphases that form them. Under such circumstances, microemulsions flow more easily through the porous medium, which enhance oil extraction performance rates.

Babadagli (2005) has written a review about development of mature oil fields. According to his review, the most common chemical injection technique, as a tertiary oil recovery method, is the surfactant solution injection due to its relatively lower cost when compared to micellar or microemulsion injection. The way by which the fluid is injected, when the chemical method is employed, is an important parameter for optimization of the technique. Continuous injection of a chemical solution may increase operation costs and/or reduce the amount of treated material. In view of this, injection of chemical solution considering the porous volume number (PV) is required in any efficient process. Thomas and coworkers (in: Babadagli, 2005) injected porous volumes of microemulsion in sandstone plugs containing $35 \%$ of residual oil, observing a linear relationship between the values of injected PV and the oil recovery. Results typically showed a $45 \%$ residual oil recovery when injecting 10 PV of microemulsion.

Santanna et al. (2009) studied the application of different types of microemulsion for enhanced oil recovery, one was prepared with a commercial surfactant (MCS), and another contained a surfactant synthesized in laboratory (MLS), (Table 4). The experiments consisted of the injection of fluids into cylindrical plug samples. During the microemulsion flooding, samples were collected as a function of time and the mass of oil recovered by the microemulsion was determined. The chemicals used to prepare the microemulsion systems were: commercial anionic surfactant (soap-sodium salt) derived from fatty acids; anionic surfactant (soap-sodium salt) synthesized in laboratory, derived from fatty acids (100wt.\% of vegetable oil containing 12 carbon atoms); isoamyl alcohol; pine oil; and distilled water. From the results obtained, one could conclude that the use of microemulsion prepared with the commercial MCS allowed for recovery indexes as high as $87.5 \%$, whilst the use of the MLS microemulsion permitted recovery indexes as high as $78.7 \%$ (Figures 12 and 13). This was due to the difference in microemulsion viscosities, corroborated by the fact that the MCS microemulsion (32 cP viscosity) could recover more oil than the MLS microemulsion (27 cP viscosity).

\begin{tabular}{|c|c|c|c|c|}
\hline $\begin{array}{c}\text { Microemulsion } \\
\text { type }\end{array}$ & $\begin{array}{c}\text { Surfactant } \\
\text { Soap (wt. \%) }\end{array}$ & $\begin{array}{c}\text { Cosurfactant } \\
\text { isoamyl alcohol } \\
\text { (wt. \%) }\end{array}$ & $\begin{array}{c}\text { Oil } \\
\text { pine oil } \\
\text { (wt. \%) }\end{array}$ & $\begin{array}{c}\text { Water } \\
\text { (wt. \%) }\end{array}$ \\
\hline MCS & 13.3 & 6.7 & 50 & 30 \\
\hline MLS & 16.7 & 8.3 & 45 & 30 \\
\hline
\end{tabular}

Table 4. Compositions of microemulsions for enhanced oil recovery assays. 


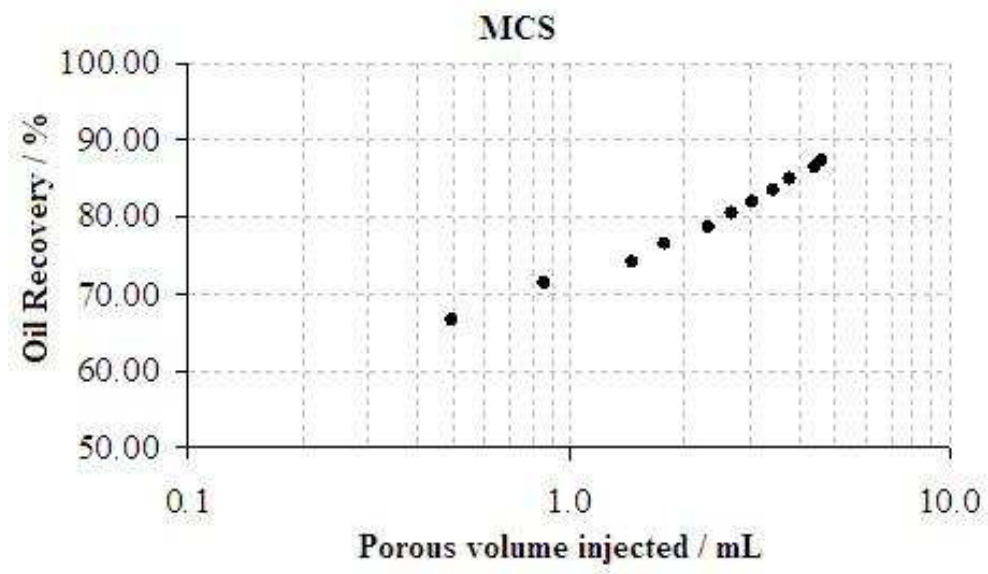

Fig. 12. Recovery factor for MCS microemulsion (Santanna et al., 2009)

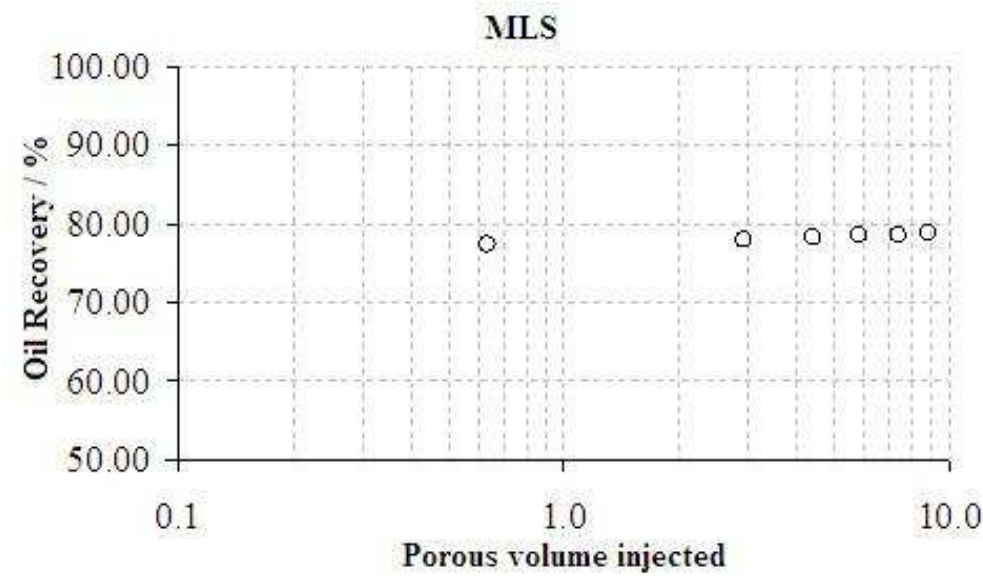

Fig. 13. Recovery factor for MLS microemulsion (Santanna et al., 2009)

\subsection{Microemulsion as alternative fuel}

The necessity of reducing gas emissions and improving the performance of engines has increased the interest in microemulsified systems as alternative fuels (Castro Dantas et al., 2001b; Ochoterena et al., 2010; Lif et al., 2010; Dantas Neto et al., 2011).

Castro Dantas et al. (2001b) verified the possibility of using microemulsified systems as alternative fuels. The authors studied new microemulsion systems containing diesel and different percentages of vegetable oils (soy, palm and castor). The main parameters that affect the formation of microemulsions are the nature of the surfactant and cosurfactant, the cosurfactant/surfactant mass ratio and composition of the oil phase. The results showed that it was possible to obtain new microemulsion systems with different oil phase composition using mixtures of diesel and vegetable oils. Among all studied systems, 
microemulsions containing diesel and soy oil could be formed over the widest composition range, indicating the possibility to apply them as alternative fuels.

Dantas Neto et al. (2011) used microemulsion systems as alternative fuels. After preparation and characterization of the systems, engine performance and emissions with the use of this new fuel were assessed. They verified that the density and viscosity of all studied systems were higher than those obtained for neat diesel. The authors also observed that these properties increased with increasing water content. According to their results for specific fuel consumption, the presence of water in microemulsions improves diesel fuel combustion. Carbon dioxide emissions were higher for the diesel/surfactant blend as well as all microemulsion fuels. Nevertheless, this difference decreased with increasing engine power when compared with neat diesel. The values of NOx emissions increased with increasing engine power, and decreased with increasing water content in the microemulsion fuels. They also observed a reduction in black smoke emissions for all microemulsion fuels tested, as compared with neat diesel. This was attributed to a better combustion reaction effected in the presence of water and surfactant, thereby reducing the formation of black smoke.

\section{Conclusion}

In this chapter, we have focused on how several microemulsion systems may be used in different areas of the oil industry, for example, in wells hydraulic fracturing, as corrosion inhibitors in pipelines, in the breakdown of water/oil emulsions, in enhanced oil recovery, and as an alternative fuel. When the microemulsion is used as a fracturing fluid, it has properties that are compatible with those of polymeric fluids, with the advantage of reducing the formation of damage. As corrosion inhibitor in pipelines, the microemulsion interacts with the metallic surface, although less intensively than if compared to surfactants in solution. Microemulsions showed good anticorrosive potential. In the breakdown of water/oil emulsions, the microemulsions presented great de-emulsifying characteristics. In enhanced oil recovery, microemulsion systems proved to be efficient in the oil extraction process. The microemulsified systems containing neat diesel or a mixture of diesel with different percentages of vegetable oils can be used as alternative fuels showing improved combustion properties in diesel engines. Overall, this chapter has attempted to demonstrate that optimization of different microemulsion systems provides important contribution to the petroleum industry, with direct implications on material processability and recovery yields.

\section{Acknowledgment}

The authors acknowledge all students, coworkers, and researchers that contributed to the publication of the material presented in this chapter.

\section{References}

Dantas Neto, A. A.; Castro Dantas, T. N.; Alencar Moura, M. C. P.; Barros Neto, E.L. \& Gurgel, A. (2009). Microemulsions as potential interfacial chemical systems applied in the petroleum industry. In: Microemulsions: Properties and Applications, Monzer Fanum, pp. 411-449, CRC Press, ISBN 978-1-4200-8959-2, Boca Raton.

Babadagli, T. Mature field development-a review. SPE, No.93884, (June 2005), pp. 1-20. 
Castro Dantas, T. N.; Dantas Neto, A. A. \& Moura, E. F. Microemulsion systems applied to breakdown petroleum emulsions. Journal of Petroleum Science and Engineering, No.32, (2001a), pp. 145-149, ISSN 0920-4105.

Castro Dantas, T. N.; Silva, A. C. \& Dantas Neto, A. A. New microemulsion systems using diesel and vegetable oils. Fuel, No.80, (2001b), pp. 75-81, ISSN 0016-2361.

Castro Dantas, T. N.; Santanna, V. C.; Dantas Neto, A. A. \& Barros Neto, E.L. Application of surfactants for obtaining hydraulic fracturing gel. Petroleum Science and Technology, Vol.21, No.7 \& 8, (2003a), pp. 1145-1157, ISSN 1091-6466.

Castro Dantas, T. N.; Santanna, V. C.; Dantas Neto, A. A.; Barros Neto, E.L. \& Alencar Moura, M. C. P. Rheological properties of a new surfactant-based fracturing gel. Colloids and Surfaces A: Physicochem. Eng. Aspects, No.225, (June 2003b), pp. 129-135, ISSN 0927-7757.

Castro Dantas, T. N.; Santanna, V. C.; Dantas Neto, A. A.; Curbelo, F. D. S. \& Garnica, A. I. C. Methodology to break test for surfactant-based fracturing gel. Journal of Petroleum Science and Engineering, No.50, (janeiro 2006), pp. 293-298, ISSN 0920-4105.

Dantas Neto, A. A.; Fernandes, M. R.; Barros Neto, E. L.; Castro Dantas, T. N. \& Moura, M. C. P. A. Alternative fuels composed by blends of nonionic surfactant with diesel and water: engine performance and emissions. Brazilian Journal of Petroleum and Gas, Vo.28, No.3, (2011), pp. 521-531, ISSN 0104-6632.

Friberg, S.E. \& Bothorel, P. (1988). Microemulsions: Structure and Dynamics, CRC Press, ISBN 0849365988, Boca Raton.

Gurgel, A.; Moura, M. C. P. A.; Dantas, T. N. C.; Barros Neto, E. L. \& Dantas Neto, A. A. A Review on chemical flooding methods applied in enhanced oil recovery. Brazilian Journal of Petroleum and Gas, Vo.2, No.2, (2008), pp. 83-95, ISSN 1982-0593.

Lif, A.; Stark, M.; Nydén, M. \& Holmberg, K. Fuel emulsions and microemulsions based on Fischer-Tropsch diesel. Colloids and Surfaces A: Physicochemical and Engineering Aspects, Vo.354, No.1-3, (February 2010), pp. 91-98, ISSN 0927-7757.

Liu, D.; Fan, M.; Yao, L.; Zhao, X. \& Wang, Y. A new fracturing fluid with combination of single phase microemulsion and gelable polymer system. Journal of Petroleum Science and Engineering, No.73, (july 2010), pp. 267-271, ISSN 0920-4105.

Moura, E. F.; Wanderley Neto, A. O.; Castro Dantas, T. N.; Scatena Júnior, H. \& Gurgel, A. Applications of micelle and microemulsion systems containing aminated surfactants synthesized from ricinoleic acid as carbon-steel corrosion inhibitors. Colloids and Surfaces A: Physicochem. Eng. Aspects, No.340, (March 2009), pp. 199-207, ISSN 0927-7757.

Ochoterena, R.; Lif, A.; Nydén, M.; Sven, A. \& Denbratt, I. Optical studies of spray development and combustion of water-in-diesel emulsion and microemulsion fuels. Fuel, No.89, No.1, (January 2010), pp. 122-132, ISSN 0016-2361.

Reyes, Y.; Rodriguez, F. J.; del Rio, J. M.; Corea, M. \& Vazquez, F. Characterisation of an anticorrosive phosphated surfactant and its use in water-borne coatings. Progress in Organic Coatings, No.52, (2005), pp. 366-371, ISSN 0300-9440.

Robb, I.D. (1981). Microemulsions, Plenum Press, ISBN 0306408341, New York.

Samuel, M. M.; Card, R. J.; Nelson, E. B.; Brown, J. E.; Vinod, P. S.; Temple, H. L.; Qi Qu \& Fu, D.K. Polymer-free fluid for fracturing applications. SPE Drilling and Completion, Vo.14, No.4, (1999), pp. 240-246, ISSN 10646671.

Santanna, V. C.; Curbelo, F. D. S.; Castro Dantas, T. N.; Dantas Neto, A. A.; Albuquerque, H. S. \& Garnica, A. I. C. Microemulsion flooding for enhanced oil recovery. Journal of Petroleum Science and Engineering, No.66, (January 2009), pp. 117-120, ISSN 0920-4105. 


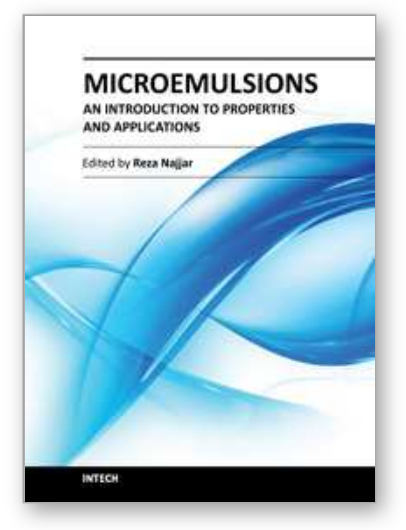

\author{
Microemulsions - An Introduction to Properties and Applications \\ Edited by Dr. Reza Najjar
}

ISBN 978-953-51-0247-2

Hard cover, 250 pages

Publisher InTech

Published online 16, March, 2012

Published in print edition March, 2012

The rapidly increasing number of applications for microemulsions has kept this relatively old topic still at the top point of research themes. This book provides an assessment of some issues influencing the characteristics and performance of the microemulsions, as well as their main types of applications. In chapter 1 a short introduction about the background, various aspects and applications of microemulsions is given. In Part 2 some experimental and modeling investigations on microstructure and phase behavior of these systems have been discussed. The last two parts of book is devoted to discussion on different types of microemulsion's applications, namely, use in drug delivery, vaccines, oil industry, preparation of nanostructured polymeric, metallic and metal oxides materials for different applications.

\title{
How to reference
}

In order to correctly reference this scholarly work, feel free to copy and paste the following:

Vanessa Cristina Santanna, Tereza Neuma de Castro Dantas and Afonso Avelino Dantas Neto (2012). The Use of Microemusion Systems in Oil Industry, Microemulsions - An Introduction to Properties and Applications, Dr. Reza Najjar (Ed.), ISBN: 978-953-51-0247-2, InTech, Available from:

http://www.intechopen.com/books/microemulsions-an-introduction-to-properties-and-applications/the-use-ofmicroemusion-systems-in-oil-industry

\section{INTECH}

open science | open minds

\author{
InTech Europe \\ University Campus STeP Ri \\ Slavka Krautzeka 83/A \\ 51000 Rijeka, Croatia \\ Phone: +385 (51) 770447 \\ Fax: +385 (51) 686166 \\ www.intechopen.com
}

\author{
InTech China \\ Unit 405, Office Block, Hotel Equatorial Shanghai \\ No.65, Yan An Road (West), Shanghai, 200040, China \\ 中国上海市延安西路65号上海国际贵都大饭店办公楼405单元 \\ Phone: +86-21-62489820 \\ Fax: +86-21-62489821
}


(C) 2012 The Author(s). Licensee IntechOpen. This is an open access article distributed under the terms of the Creative Commons Attribution 3.0 License, which permits unrestricted use, distribution, and reproduction in any medium, provided the original work is properly cited. 